\title{
CORRELATION OF URINARY PROTEIN CREATININE RATIO VERSUS URINARY TRACT INFECTION IN ASSESSMENT OF SEVERITY OF PRE-ECLAMPSIA
}

Abd El-Moneim Ali Fawzy, Suzan Elsharkawy, Dina Aly Kholeif*, Noura Abdelhamid Hassanin

Department of Obstetrics and Gynecology, Department of Medical Microbiology and Immunology*, Faculty of Medicine

\section{INTRODUCIION}

Hypertensive disorders of pregnancy contribute to most of the maternal morbidity and mortality. Preeclampsia is a disorder of pregnancy by which every organ can be affected. Elevated blood pressure above $140 / 90 \mathrm{mmHg}$ and proteinuria are the main diagnostic criteria of preeclampsia. Proteinuria is described a urine protein: creatinine ratio equal or more than 0.3

Preeclampsia can be categorized into "severe" and "non severe." According to the blood pressure measurement, presence of proteinuria, symptoms like headache, visual disturbances, upper abdominal pain or epigastric pain, signs like decreased urine output, elevated serum creatinine level, elevated liver transaminases, thrombocytopenia, pulmonary oedema, and fetal growth restriction.

UTI which is one of the most common infections in pregnancy claimed to play a part in preeclampsia by enhancing maternal systemic inflammatory response and endothelial cell dysfunction which cause placental ischemia.

\section{AMM OF THE WORK}

The aim of this study was to correlate between urinary protein creatinine ratio and urinary tract infection in assessment of severity of preeclampsia.

\section{PATIIENTS AND MIETHODS}

This prospective cross-sectional study conducted on 50 patients diagnosed with preeclampsia who are admitted to El Shatby university hospital to assess severity of preeclampsia using albumin creatinine ratio and correlate it with urinary tract infection in preeclamptic patients after signing their informed consent.

Two groups were enrolled. Based on Urinary tract infection, Group A (25 cases) included preeclamptic patients without urinary tract infection whereas Group B (25 cases) included preeclamptic patients with urinary tract infection and the proteinuria was assessed using protein creatinine ratio and nfection was assessed using urine analysis and urine culture.

Inclusion criteria:

1.Pregnant in the third trimester

2.Hypertension plus proteinuria: Protein: creatinine ratio $\geq 0.3$
3.Pregnant with signs and symptoms of urinary tract infection as dysuria, urgency, frequency, and these were included in group B.

All cases were subjected to blood pressure monitoring, ultrasound examination, full laboratory investigations and proteinuria assessment using protein creatinine ratio. Urine culture and antimicrobial susceptibility were performed in group B patients. The severe features of preeclampsia have been assessed and compared between the two groups.

\section{RESULTS}

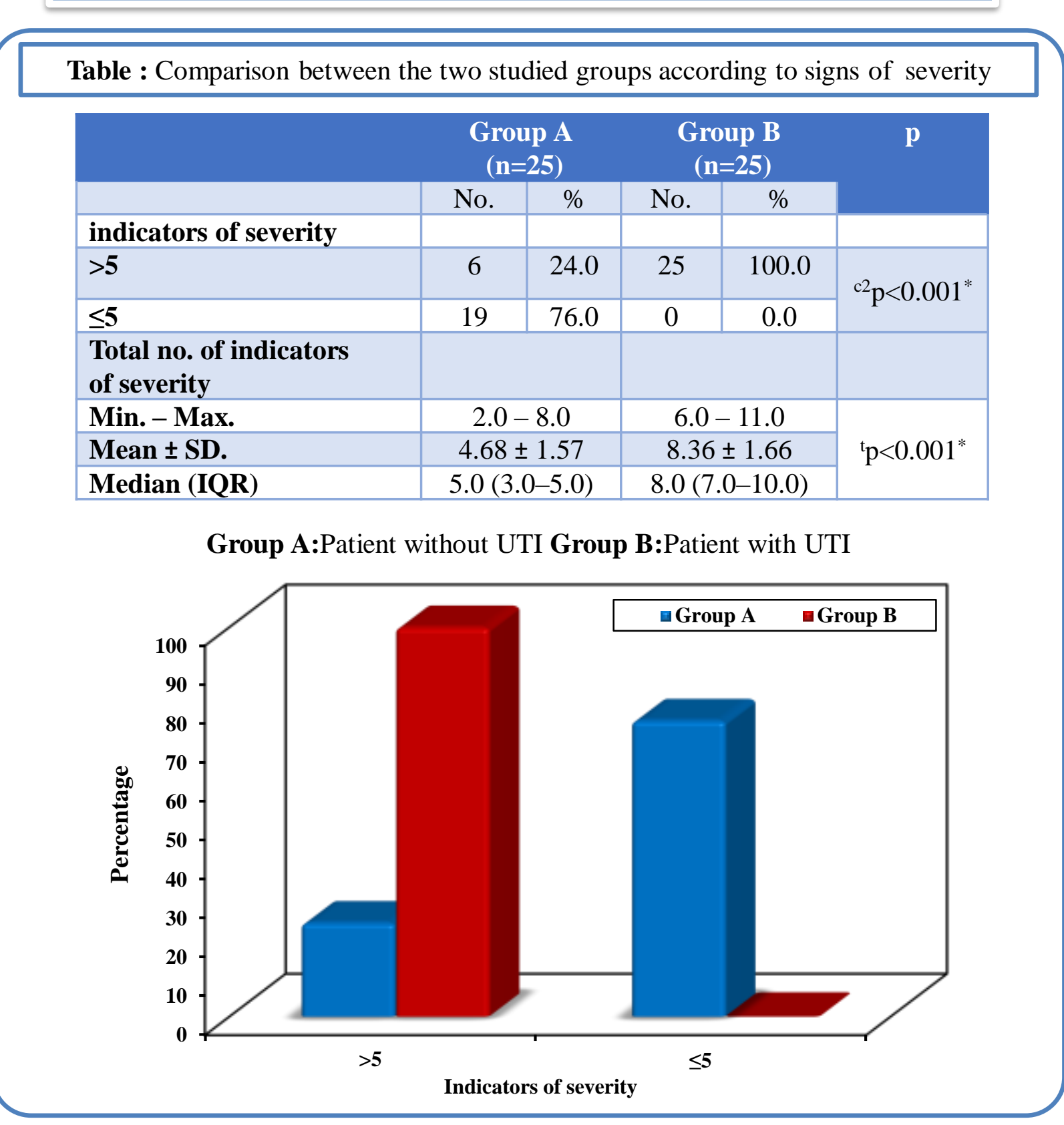

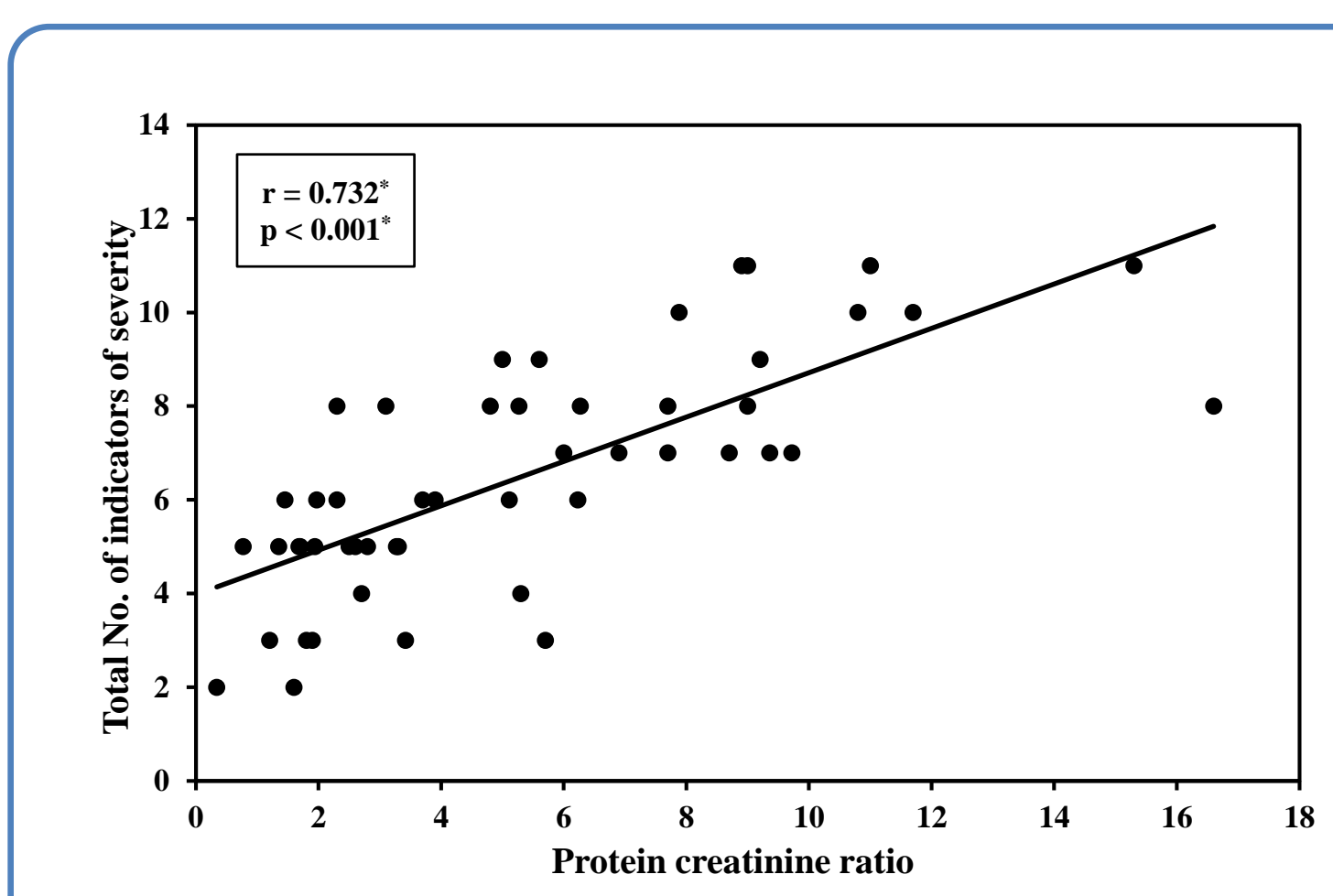

Figure: Correlation between total number of indicators of severity with protein creatinine ratio and in Total group

\section{CONCLUSION}

- Protein creatinine ratio positively correlates with the severity of preeclampsia, in addition to revealing a statistically significant increase in values in preeclamptic patients with UTI.

- urinary tract infection (UTI) during gestation is associated with increased severity of preeclampsia.

- Urine analysis and urine culture should be done in severe preeclamptic patients to exclude presence of urinary tract infection.

- Escherichia coli was found to be the most prevalent organism isolated in preeclamptic patients with UTI.

$$
\begin{gathered}
\text { 20210Alexandria Faculty of Medicine } \\
\text { CC-BY-NC }
\end{gathered}
$$

